\title{
Identifying Divergent Foster Care Careers for Danish Children
}

Fallesen, Peter

Published in:

Child Abuse \& Neglect

DOI:

10.1016/j.chiabu.2014.08.004

Publication date:

2014

Document version

Early version, also known as pre-print

Document license:

Unspecified

Citation for published version (APA):

Fallesen, P. (2014). Identifying Divergent Foster Care Careers for Danish Children. Child Abuse \& Neglect, 38(11), 1860-1871. https://doi.org/10.1016/j.chiabu.2014.08.004 


\title{
Identifying Divergent Foster Care Careers for Danish Children
}

\author{
Peter Fallesen, M.Sc. \\ Rockwool Foundation Research Unit \\ Department of Sociology, University of Copenhagen
}

Short title: Divergent Foster Care Careers

Author's note: E-mail: pf@rff.dk. Fax: +45 33344899 Phone: +45 33344812

Rockwool Foundation Research Unit, Sølvgade 10, 2. tv, DK-1307 Copenhagen K, Denmark.

This paper benefited from discussions with Signe Hald Andersen, Mads Meier Jæger, Anette

Fasang, Emily Putnam-Hornstein, Elizabeth Roberto, Rasmus Legêne, and Christopher

Wildeman. The author thanks seminar participants at AQS, Copenhagen 2011, CSSR, UC

Berkeley 2013, and three anonymous reviewers for additional comments. The Rockwool

Foundation funded the study. The author is also grateful for additional funding from the Egmont

Foundation, The Danish-American Foundation, and the Oticon Foundation. 


\begin{abstract}
Foster care children who experience placement disruption and foster care instability are at elevated risk for a host of poor outcomes, yet little work considers what these unstable foster care careers look like or what causes them. In this article, I start by using previous studies on foster care drift, instability, and placement disruptions to define the unstable foster care career as a subset of foster care careers. I then use administrative data on 30,239 Danish children born 1982-1987 who entered foster care to generate nine foster care careers, two of which meet the criteria for an unstable career. Children with a high number of risk factors associated with foster care entry were also the most likely to enter an unstable career. I end by discussing implications for recent studies of the effect of foster care on children's later life outcomes and the relevance of the findings for practitioners.
\end{abstract}

Keywords: administrative data; foster care; instability; sequence analysis 
Foster care is intended to provide children with the best possible opportunity for personal development and stability when their immediate family is unable to secure them a safe and stable upbringing. Nevertheless, some children's placement trajectories end up mirroring the instability they experienced prior to entering foster care (e.g., Andersen, 2012; Havlicek 2011). Previous studies have examined aspects of such unstable foster care trajectories, including foster care drift where children move aimlessly through the foster care system, without reaching a permanent placement, adoption, or successful reunification (e.g., Andersen, 2012; Hartley, 1984), placement instability (e.g., Havlicek, 2010; Lewis, Dozier, Ackerman, and Sepulveda-Kozakowski, 2007; Newton, Litrowik, and Landsverk, 2000; Ward, 2009), foster care disruptions (e.g., Oosterman, Schuengel, Slot, Bullens, and Doreleijers, 2007; Proch and Taber, 1984), and foster care reentry (e.g., Courtney, 1996; Shaw, 2006; Wells and Guo, 1999). Nevertheless, the literature has not produced a taxonomy of children's foster care trajectories.

This article adds to the literature in two ways. First, it provides an outline for a theoretical approach to studying children's lives in foster care with a focus on instability. Using life course theory, the approach nests foster care trajectories within the sociological concepts of the life course and the career. Earlier studies have predominantly examined foster care instability using points in time or aggregated measures of placement moves or disruptions. Instead, I study a foster child's entire childhood and adolescence. Framing a foster child's childhood and adolescence as a career enables me to draw upon previous sociological research on individual's trajectories through more or less formal social institutions, generating a theoretical perspective that embeds foster care experiences inside the early life course.

Second, I use Dynamic Hamming Matching (DHM), a recent development in sequence analysis, to identify distinct patterns of foster care trajectories among all Danish foster care 
children born between 1982 and 1987. The data hold monthly information on children's foster care placement, and unique personal identifiers make it possible to link children with their parents. The methodological approach simultaneously incorporates duration of time spent in foster care, number of foster care placements, and the timing of placement shifts, reunifications, and reentries.

\section{Background}

Foster care children experience a larger share of adverse events over the early life-course than most other children, such as unstable living conditions, exposure to parents with substance abuse issues, paternal relationship dissolution, etc. (see Simkiss, Thorogood and Stallard, 2013 for a recent review). In addition, substantial shares of children across Western countries spend time in foster care. The cumulative risk of ever being placed in foster care was just under 6 percent for American children in 2005 (Wildeman and Emanuel, 2014), and other Western countries, such as Denmark, reported similar rates of cumulative risk at around 5 percent for the same year (Fallesen, Wildeman, and Emanuel, 2013). Because notable shares of children enter foster careand because foster care may have lasting impact on children's lives (Berger, Bruch, Johnson, James, and Rubin, 2009; Doyle, 2007; 2008; Fallesen, 2013b; Warburton, Warburton, Sweetman, and Hertzman, 2014) — it is important to thoroughly address foster care placement and foster care instability as childhood experiences.

In this study, I outline a theoretical and methodological approach to study children's foster care experiences that nests experiences within the concept of a foster care career (see Barley (1989) for a discussion on the sociological origin of studying careers). A foster care career describes childhood trajectories in a home replacement setting that children enter because 
of maltreatment, parental inattention or illness, delinquency, or other forms of unwanted behavior. It is a concept that jointly considers the timing and amount of: (a) time spent in foster care; and (b) events, such as entry into foster care, moves between placements, reunification with biological family, and potential reentry into foster care. Children's experiences in foster care, as well as the timing of the experiences, jointly constitute the foster care career. Thus, it is necessary to consider both aspects when judging whether a child experiences an unstable foster care career.

\section{Defining Unstable Foster Care Careers}

A complex foster care career is not necessarily the same as an unstable foster care career. Social services will instantaneously place children at immediate risk of serious maltreatment in shortterm emergency care. Only thereafter will social services thoroughly assess the child in order to provide an adequate type of foster care. In this case, the child would experience at least one short-term foster care placement before entering a properly assessed foster care placement. A single short-term placement might therefore not necessarily represent instability, but a number of short-term placements following upon each other would indicate that a proper assessment of the child's needs has not taken place (Berrick, 1998).

Prior research on foster care instability focused on network disruptions (Perry, 2006), extended time in foster care and multiple placements (Usher, Randolph, and Gogan, 1999), repeated moves among foster care placements (Proch and Taber, 1985), and failures to reunify with biological parents (e.g., Wells and Guo, 1999). Failed reunifications present a different aspect of instability than moves between foster care placements. A foster care placement is in itself a disruption of the life the child has led. A failed reunification entails both not meeting the 
expectations involved in returning to the parents, as well as a new disruption. Thus, an unstable foster care career consists of a combination of a long time spent in foster care, more than one short-term placement, moves between placement sites, and failed reunifications.

\section{Foster Care in a Danish Context}

I use Danish administrative data to identify unstable foster care careers. Denmark provides an interesting case because it combines a strong and involved welfare state (Esping-Andersen, 1990) with low social inequality (Lancee and Van de Werfhorst, 2012) and high foster care caseloads (Fallesen, Emanuel, and Wildeman, 2013). At the same time, children who enter foster care tend to come from single parent or cohabiting parent homes with younger parents that often have low levels of education and poor labor market affiliation (e.g., Andersen and Fallesen, 2010; Egelund, Hestbæk, and Andersen, 2004; Ejrnæs, Ejrnæs, and Frederiksen, 2011). (A recent systematic review by Simkiss, Thorogood, and Stallard (2013) finds that these risk factors appear to be similar across national contexts). In addition, Danish data on foster care cover the entire population and offer a very high level of detail.

The Danish child welfare system has a number of unique aspects. Historically, the system has relied on voluntary and family-oriented interventions (Hestbæk, 2011). The focus on voluntary participation is also evident from the fact that more than 85 percent of Danish foster care placements between 1980 and 2005 were with parental consent (Andersen and Ebsen, 2010). Yet Andersen and Ebsen (2010) argue that a large share of voluntary placements were in lieu of involuntary placements that would leave the biological parents with fewer rights to visitations, less influence on the child's life, etc. Especially in the 1990s (but also later), the Danish foster care system stressed the importance of foster care children's experience of 
continuation — not only in terms of placement stability but also through continuing contact with the birth parents while the child was in foster care (Hestbæk, 2011). When giving parents the choice between agreeing to a voluntary placement — thereby retaining easier access to visits and other forms of interaction with their child — and having their child involuntary placed in foster care, it stands to reason that most parents will choose the first option.

The focus on ongoing contact with biological parents is also evident in the fact that Danish social services use long-term foster care placements and very infrequently terminates parental rights. That is, whereas children bound for long-term out of home placement in, for example, the U.S. tend to exit to adoption or guardianship (Gendell, 2001), Danish children remain in the foster care system. Among Danish children, teenagers have the highest risk of first time entrance into foster care (Fallesen, Emanuel, and Wildeman, 2013). The age-specific risk is similar to what is observed in, for example, England (Department of Education, 2013) whereas comparative estimates from the U.S. indicate that it is the youngest children who have the highest risk of entering foster care (Wildeman and Emanuel, 2014).

Last, although Danish social services mostly use foster home care and more rarely kinship care, they also widely use residential and congregate foster care. The type of foster care placement a child enters often depends on the child's age, but also traditions in the child's local municipality (Frederiksen, 2012). Social services also place older children without special needs at continuation schools (or boarding schools) that cover $8^{\text {th }}$ to $10^{\text {th }}$ grade. At continuation schools, out of home placed children live among peers who are not at the school because of a foster care placement.

Whereas placement at a continuation school is a softer option, social services place children with behavioral issues or other types of special needs in treatment care instead. 
Treatment care facilities have a higher staff-to-child ratio than both residential and congregate care institutions and continuation schools. Treatment care facilities also have a more specific social-pedagogical aim than the other types of group homes and forms of congregate care.

Overall, Danish social services aim to provide children who are unable to reunify with stable, long-term foster care, instead of opting for alternative forms of permanency. Instability in the Danish system, however, functions similarly as in permanency-focused foster care systems: children bounce around the system, without ending up with a stable residence, moving from one foster care placement to the next.

\section{Analyzing Foster Care Experiences as Careers}

Each child's foster care experience is unique, but children have certain types of foster care careers. A foster care career is a unit that incorporates events, timing, and duration of distinct foster care experiences. To locate distinct careers in the data requires a method that groups foster care trajectories together, based on children's entire foster care experience. The method must be able to handle "both a fair amount of pattern and a fair amount of fluctuation" (Abbott, 1990:140) in the data.

Sequence analysis methods (see Abbott, 1995; Abbott and Tsay, 2000 for an introduction) locate collective patterns (or rhythms) among individual trajectories. Whereas other types of models with similar aims, such as group based trajectory methods (e.g., Nagin, 1999), assume an underlying distribution of the data, sequence analysis does not make assumption about how the data are distributed. Instead, sequence analysis groups similar trajectories through cluster analysis. Because sequence analysis relies on cluster analysis, it is not possible to test hypotheses about whether, for example, two clusters of careers are statistically distinct from each 
other. Instead, sequence analysis is a heuristic tool that allows researchers to locate patterns in complex data. The lack of distributional assumptions and the inductive approach to data make sequence analysis a good tool for generating theory based on large quantities of empirical data when there is little knowledge of the underlying data generating processes.

Early versions of sequence analysis relied on the researcher to judge how to weigh differences between trajectories. The judgments had a substantial impact on how the method grouped trajectories together, which made critics point out that such arbitrariness raised serious validity issues for the results of analysis (see Wu, 2000). The criticism led to the second wave of sequence analysis methodologies (see Aisenbrey and Fasang, 2010 for review). Lesnard (2010) proposed an updated version of optimal matching named Dynamic Hamming Matching (DHM). Instead of weighting based on more or less arbitrary decisions made by the researcher, the rhythms of the data generate the weights, whereby DHM generates groups that are closer to the data.

[Figure 1 about here]

Figure 1 describes the data and the matching procedure. Here I consider two children's foster care experiences for twelve months. DHM calculates an overall transformation cost (described in detail below) for aligning two sets of sequences by aggregating the transition cost for each sequence period. The transition cost is 0 when two children's sequences align (Figure 1b). When the two children are in different states (Figure 1c), the transition cost for aligning the two states to each other depends on how often all children in the data move between those two states around that period. If, for example, children in the sample often move between home and second placement around month 7, the transition cost for aligning home and second placement at month 7 is low. If the move happens rarely, the transition cost is high. The rarer a move between 
two foster care states is in the data at a specific time during a child's childhood, the less similar two children's foster care trajectories will be if one child is in one of the two states, and the other child in the other state. Summarizing the transition costs across sequences for all pairs of children in the data then yields a measure for how dissimilar any two childhood-trajectories in the data are from each other.

Using cluster analysis, we can then group children who have similar foster care trajectories together, thereby creating the average career for each of these groups. This makes it possible to graphically show the different career types, as well as examine what characterizes children who end up having certain types of foster care careers.

\section{Method}

\section{Data}

The study uses administrative data on all Danish children born between 1982 and1987 who spent time in foster care. Although data are available from 1980, I use 1982 as the starting cohort because it is the first year where there exists complete information concerning the children's parents prior to the child's entry to foster care. 1987 is chosen as the final cohort because the Danish child welfare system began to undergo a series of reforms of both substantial and a dataoriented natures in 2006 (Hestbæk, 2011), and children born 1987 would have exited the system no later than 2005 .

Three substantial reforms took place during the study period (see Andersen and Ebsen, 2010; Hestbæk, 2011). The first, enacted in 1993 and studied by Fallesen (2013b), changed the average duration of foster care stays across cohorts, but did not change the average number of foster care placements or age at first placement across cohorts. Thus, later born cohorts spend 
more time in foster care, but did not seem to experience more or less placement changes. The reform emphasized children's need for continuity of attachment, underlining both the child's need for contact with the natural parents during foster care placement, but also gave caseworkers the possibility of prolonging an ongoing foster care placement.

The second reform, enacted in 1998 as part of a larger social services reform and studied by Fallesen (2013a), placed increased emphasis on the reporting responsibility of teachers, kindergarten teachers, coaches, youth workers and other individuals with regular contact with children, when suspecting child maltreatment or other forms of failure to thrive. The 1998 reform increased the share of child population in foster care in any given day from around 0.95 child out of 100 to around 1.08 child out of 100 (Andersen and Ebsen, 2010; Fallesen, 2013a). Thus, later born cohorts might enter foster care at a slightly younger age and at a slightly higher rate than earlier born cohorts might. Nevertheless, there is no indication that the reform affected the number of placements children in foster care experienced.

The third reform, enacted in 2001, introduced new after-care measures for young adults, who had aged out of foster care, and also aimed at increasing casework quality (Hestbæk, 2011). Again, there is no indication that this affected the number of placements a child experienced while in foster care.

Statistics Denmark recorded and provided the data. All data originate from administrative registers used in the daily handling of foster care cases in Danish municipalities. The municipalities transfer the data to Statistics Denmark annually. Data include all Danish foster care cases for each year, so there is no attrition or non-response (Statistics Denmark 2013). Statistics Denmark reclassified a subgroup of interventions in 1993 from being foster care placement to be family-oriented interventions instead. In the interest of comparability, these 
subgroups have been recoded as foster care placements. This is similar to the approach used by Fallesen (2013b).

30,234 Danish children from the 1982-1987 birth cohorts entered foster care at some point during childhood, which amounts to 8.9 percent of the cohorts. Figure 2 shows the density distribution of foster care duration for the cohorts. Most children spent very little time in care. The majority of the distribution lies within three years, and on average a child spent 35.49 months in foster care. Since Denmark does not use permanency but instead keeps children in long-term care if reunification is not an option, this also includes all children in stable long-term care, who in permanency-based systems would have been adopted instead. Foster care was thus common, but most foster care children did not spent much time in it.

[Figure 2 about here]

I structure the data in monthly sequences for each child's entire childhood. Danish children reach adulthood at age 18 , so the data hold $12 * 18=216$ monthly sequences per child. For each month, I have information on whether the child was in foster care or not. If the child was in foster care, I also record what number placement it was. A change of placement is either (a) a move from one foster care site to another foster care site or (b) a move into foster care after having spent some time at home. Figure 1a shows an example of the data structure.

To examine what characterizes children who enter unstable foster care careers, I also obtain information about socioeconomic background, family status, and living conditions. To avoid foster care placement affecting parental characteristics, I use information from the year prior to the child entering foster care. I used a unique identification variable based on the social security number all Danish inhabitants receive at birth or upon immigration to link children to parents. Table A1 in appendix shows descriptive statistics for the sample and details for how 
variables were coded.

\section{Results}

\section{Foster Care Careers}

Using DHM and cluster analysis, I find nine distinct career types best define the 1982-1987 cohorts. Figure 3 shows the state distribution plot for the careers. That is, Figure 3 shows the distribution of foster care placements and home stays for all months of the childhood for each career type. If we, for example, look at the career labeled Stable 3, we can see that for this career type all children were at home until around age ten, and then rapidly start to enter first placement thereafter. Figure 4 plots the trajectory for each child as an index line, and gives a better picture of timing of event. If we again look at Stable 3, we see that children who experience Stable 3 all move into first placement between age 11 and age 15, at a pretty even pace across the four years of age. Together the two figures capture the distribution and the intensity of the nine careers. Table 1 shows descriptive statistics for the career types.

[Figure 3 about here]

[Figure 4 about here]

[Table 1 about here]

The career types can then be further divided into two groups. The first group consists of short-term careers, children with short stays and a low share of children aging out of care at age 18. There are two short-term careers, and they differ in foster care entry age and foster care duration. The second group is careers with longer placements and with a high share of children aging out of care. The long-term career types differ on number of placements, timing of placement changes, age at first placement, and number of failed reunifications. 23,376 children 
$(77.3 \%)$ experienced a short-term career, and 6,863 (22.7\%) experienced a long-term career. [Table 1 about here]

Two career types stand out as unstable (Complex 1 and Complex 2). Children who experience one of the two have multiple short placements and failed reunifications. Children who experience Complex 2 have at least four different foster care placements, with some children experiencing their fourth placement before their second birthday. The average number of placements for this career type is 6.13 , with an average of 2.47 failed reunifications. Children who experience Complex 1 have an average of 3.50 placements and 1.09 failed reunifications. Both types describe foster care trajectories with multiple incidents of short term placements and failed reunifications.

Comparatively, the five other career types (Stable 1, Stable 2, Stable 3, Two stop 1, and Two stop 2) describe foster care trajectories with few (if any) changes of placement. The Two Stop types differ from the Stable by having the children enter a short first placement, and then move into a long-term placement, where children with Stable career types move directly into a long-term placement. Besides this, the main differentiating factor for these careers is the timing of first placement. All five types do show some volatility when children are in their teens, but are nonetheless substantially more stable than Complex 1 and Complex 2 (see Table 1).

\section{Placement Settings}

Table 2 reports the share of children in each career type who spent time in different foster care settings. Children in long-term careers are all more likely to spend time in family foster care (i.e., predominantly with a non-kin professional foster parent). Career types with a short first placement are also more likely stay in congregate and institutional care. Some congregate and 
institution care homes do provide children with a permanent place to live, but social services often use such places for short-term emergency placements. Social services then move the child once they have made thorough assessment of the case.

[Table 2 about here]

Short term 1, Short term 2, and Stable 3 use boarding and continuation schools to a higher extent than the other career types. The choice of different foster care settings is likely age related. Andersen and Fallesen (2010) showed that risk factors predict foster care entrance differently across age for Danish children. Parental characteristics are good predictors for young children's entrance into foster care, but parental characteristics have little predictive power for older children's entrance into foster care. Older children seem to enter foster care for reasons distinct from those of younger children, which could explain why older children spend their time in different settings than younger children do.

Children with unstable careers (Complex 1 and Complex 2) and late onset careers (Stable 3 and Two stop 2) are most likely to enter treatment care (i.e., a congregate care setting that specializes in treating behavioral issues). Again, age related differences in reasons to enter foster care could explain why the late onset careers have higher rates of entrance into treatment care. Prior studies link foster care instability with behavioral issues (Rubin et al., 2004; Rubin, O'Reilly, Luan, and Localio, 2007). If behavioral issues lead to instability (or instability leads to behavioral issues), it explains why children with complex careers are more likely to enter treatment care even though they enter foster care at a young age.

\section{Entering an Unstable Career}

To examine what characterizes children who enter unstable careers, I use logit models to predict 
entrance into the two unstable career types (Complex 1 and Complex 2). To both capture predictors among all children who enter foster care, as well as only children in long-term careers, I use two samples: (a) all children in the sample $(N=30,239)$, and (b) only children in long-term foster care $(N=6,863)$. Because foster care placements may impact parental characteristics, the models use explanatory variables measured the year before the child entered foster care for the first time. Table 3 reports results from the logit models.

[Table 3 about here]

Complex careers are more likely to happen to children who have at least one nonresident parent or who experience housing instability while living with a biological parent. Among all children in foster care, children who moved the year prior to first placement have just above oneand-a-half fold higher risk of entering an unstable career. The association drops to a one-fold higher risk when only comparing children with unstable careers to other children with long-term careers. (Yet, as noted by, e.g., Breen and Karlson (2013), the reader should keep in mind that results across logit models are not directly comparable). The odds ratios for being an orphan or having a deceased mother are very high (38.06 and 24.54) for the full sample, but again is muted when only examining children in long-term careers.

Children with low educated mothers, mothers who receive early retirement pension, are unemployed, or are outside-the-labor force also have higher likelihood of entering an unstable career. Children with mothers who have education above primary level (i.e., high school diploma or higher) have half the risk of entering an unstable career compared to the full sample and threefifths of the risk when limiting the sample to children in long-term careers. Having a mother on early retirement pension leads to a 0.41 fold higher risk of an unstable career among the full sample, and a 0.12 fold higher risk in the long-term sample, though the latter is not significant. 
The risk for children whose mothers are outside the labor force is roughly twice as high as the risk for children with early retired mothers in both samples. Children with mothers on sick leave have a lower risk (odds ratio 0.14 and 0.20 ) compared to employed mothers. Earlier work (Ejrnæs, Ejrnæs, and Frederiksen, 2011) found that low or non-existing maternal labor market attachment were a risk factor for entering foster care. The results from my study indicate that poor labor market attachment is also a risk factor for entering an unstable foster care career, conditioned on entering foster care.

Children with Danish or Western background are two to three times as likely to enter complex careers as children with Non-western backgrounds in the full sample are, but only twice as likely in the long-term sample. Non-western children spend shorter periods in care, possibly because of different family structures than among Danish and Western families (most Nonwestern immigrants in Denmark come from countries with predominantly Muslim populations). Ubbesen, Petersen, Mortensen, and Kristensen (2012) found similar results when studying the risk of re-entry into foster care, and argued that both differences in cultural contexts, as well as the low supply of foster families with an appropriate cultural background, might drive the ethnic differences.

Among children who enter foster care, it is those with mothers who gave birth at an older age that tends to enter unstable careers. The odds ratio per year for the full sample is 1.03 , and 1.02 for the long-term sample. Whereas the odds ratios are small, the fact that the mother's age is a continuous variable means that there will be substantial differences in probabilities for entering complex careers for, for example, mother's who were 20 years old when giving births, and mothers who were 30 years old. A young mother's main challenge may have been a lack of education and experience, which led to her child entering foster care. Older mothers with 
children in foster care might have faced different challenges, such as somatic and mental health conditions or substance abuse, which could lead to their children ending up with unstable foster careers (see also Putnam-Hornstein and Needell, 2011).

Overall, the main risk factors predicting entrance into an unstable foster care careers are similar to those predicting entrance into foster care in the first place. Children who are likely to enter unstable foster care careers seem to be among those in the most need and with the greatest concentration of vulnerabilities.

\section{Discussion}

Foster care placement is common for both Danish and American children, but very few studies examine the life of the substantial share of children who grow up in institutions or foster families. Recent work has tied the study of foster care to the literature on network disruptions (Perry, 2006), parental imprisonment and networks among the urban poor (Wildeman and Waldfogel, forthcoming), and identity theory (Fallesen, 2013b). However, these studies have not conceptualized the life course for children in care.

This study has linked children's foster care trajectories to the sociology of careers in order to generate an approach to understanding children's foster care experiences across their childhood. The unstable foster care career is a subgroup of particular interest. Children who enter foster care come from unstable backgrounds. Social services place children in foster care to provide stability. Yet, a substantial share of children who enter foster care never experience stability. Understanding the nature of unstable careers, as well as gaining knowledge of who enters them, is a first step in helping children avoid such careers.

In the current analysis, I use Dynamic Hamming Matching to identify nine typical foster 
care careers for all Danish foster care children born 1982-1987. The nine careers consisted of two subgroups: short-term care careers and long-term care careers. Two of the long-term foster care careers met the definition of unstable foster care careers. More than a quarter of all children in long-term care experienced one of the two unstable careers. These children aged out of care, experienced multiple placements, and had failed reunifications. Predictors for who among foster care children entered unstable foster care careers were similar to the predictors for who entered foster care among the entire child population. Children with a high number of risk factors for entering foster care were also those most likely to enter unstable careers when in foster care.

Although it is difficult to know how the results presented in this study directly generalize to other national contexts given differences in welfare state regimes and foster care practices, the results are highly relevant to an international readership for two reasons. First, whereas the dataset used is unique in the sense that it is drawn from the Danish registry data, it aligns well with, for example, recent U.S. based efforts in merging a number of different administrative registers (Putnam-Hornstein, Needell and Rhodes, 2013; United States Government Accountability Office, 2013). As such, the analysis provides guidance for future studies of a similar kind. Second, the study offers an approach that both addresses and orders children's foster care experiences as a single unit. This enables researches to view the sum of experiences as a whole without losing the distinct contribution of individual events. As such, the study has tried to outline a methodology and a vocabulary for future discussions of the types of experiences children have in foster care.

\section{Limitations}

The use of sequence analysis allows me to approach data inductively without making 
assumptions about underlying distributional forms. This flexibility does come at a price, though — without distributional assumptions, it is not possible to test whether two children grouped in different careers had statistically distinct substantially different foster care experiences. Thus, it is not possible to evade a certain degree of arbitrariness in the results. Nevertheless, Dynamic Hamming Matching at least removes some of the arbitrariness from the way I group children's foster care trajectories together. Additionally, the results on the differences in the foster care setting that children experience across careers indicates that the careers represents qualitatively different foster care experiences.

Another limitation of the study concerns the nature of children's individual foster care experiences. A number of studies documents the mutually reinforcing process of negative behavioral patterns and foster care instability (e.g., Newton, Litrowik, and Landsverk, 2000; Rubin et al., 2004; Rubin, O'Reilly, Luan, and Localio, 2007). Yet the data used does not allow me to examine important characteristics of the children. In addition, the data does not allow me to examine the reasons for why children entered foster care or their relationships with their caseworkers - both known to be important factors for the possibility of instability (e.g., Ward, 2009). Incorporating such information would create a more complete picture of children's foster care careers, but is outside the scope of this study.

\section{Implications}

In recent years, a handful of studies have sought to estimate whether children benefit from entering care or if foster care has a negative impact on later life outcomes (Berger, Bruch, Johnson, James, and Rubin, 2009; Doyle, 2007; 2008; Warburton, Warburton, Sweetman, and Hertzman, 2014). The studies provided mixed evidence, with some finding negative effects 
(Doyle, 2007; 2008; partly Warburton et al., 2014), other positive effects (Warburton, Warburton, Sweetman, and Hertzman, 2014), and some null effects (Berger, Bruch, Johnson, James, and Rubin, 2009). A recent article (Fallesen, 2013b) demonstrated that the duration of foster care has causal effect on later life outcomes, which may explain part of the mixed findings. The present study indirectly expands on the literature on the effect of foster care, by exploring what happens to foster care children while they are in foster care. One child may remain in the same foster care placement until reaching adulthood, whereas another child moves from placement to placement, spending time in both foster home care, residential care, and treatment care. If the children studied in the recent work on the effect of foster care experienced different careers across the studies, it could explain part of the discordant findings. Future studies could gain much from considering what type of foster care career a child experienced. In addition, more qualitative inquiries could also help develop a broader understanding of the mechanisms that cause children to experience unstable careers, and in return how these careers affect children's life outcomes.

In regard to social work practice, the results suggest that children from backgrounds with a high number of risk factors are also the children who are most likely to experience unstable foster care careers if they enter foster care. A growing literature has sought to develop predictive risk models to aid caseworkers in identifying children at risk of maltreatment (e.g., PutnamHornstein and Needell, 2011; Vaithianathan, Maloney, Putnam-Hornstein, and Jiang, 2013). A possible extension of this could be to develop models that aimed to identify the children at most risk of having an unstable foster care career using characteristics measured at the time of entry into foster care. Caseworker experience, among other aspects, is known to be associated with less risk of placement disruption. Predictive models could be used as a tool for caseworker 
assignment, so that the most experienced caseworkers would be assigned cases with the highest risk of developing into an unstable career. Yet, there is a need for more research into predictors of unstable foster care careers before this will be a viable possibility. This study has nonetheless provided some indications of predictors: the children from the most unstable backgrounds - who likely need the stability provided by state care the most - appear to be the ones who are at highest risk of never experiencing stability while in state care.

\section{References}

Abbott, A. (1990). Conceptions of time and events in social science methods: Causal and narrative approaches. Historical Methods: A Journal of Quantitative and Interdisciplinary History, 23, 140-150.

Abbott, A. (1995). Sequence analysis: New methods for old ideas. Annual Review of Sociology, 93-113.

Abbott, A., \& Tsay, A. (2000). Sequence analysis and optimal matching methods in sociology: Review and prospect. Sociological Methods \& Research, 29, 3-33.

Aisenbrey, S., \& Fasang, A. E. (2010). New life for old ideas: The" second wave" of sequence analysis bringing the "course" back into the life course. Sociological Methods \& Research, 38, 420-462.

Andersen, S. H. (2012). Complex patterns: On the characteristics of children who experience high and low degrees of foster-care drift. British Journal of Social Work. Published online.

Andersen, S. H., \& Fallesen, P. (2010). A question of class: On the heterogeneous relationship between background characteristics and a child's placement risk. Children and Youth 
Services Review, 32, 783-789.

Barley, S. R. (1989). Careers, identities, and institutions: The legacy of the Chicago School of Sociology. In M. B. Arthur, D. T. Hall \& B. S. Lawrence (Eds.): Handbook of career theory (pp.45-65). New York: Cambridge University Press.

Berger, L. M., Bruch, S. K., Johnson, E. I., James, S., \& Rubin, D. (2009). Estimating the "impact" of out-of-home placement on child well-being: Approaching the problem of selection bias. Child Development, 80, 1856-1876.

Berrick, J. D. (1998). When children cannot remain home: Foster family care and kinship care. The Future of Children, 8, 72-87.

Breen, R., \& Karlson, K. B. (2013). Counterfactual Causal Analysis and Nonlinear Probability Models. In S. L. Morgan (Ed.): Handbook of Causal Analysis for Social Research (pp. 167-187). New York: Springer.

Department of Education (2013). Children looked after in England (including adoption and care leavers) year ending 31 March 2013. London, UK: Department of Education.

Egelund, T., Hestbæk, A.-D., \& Andersen, D. (2004). Små børn anbragt uden for hjemmet. 04:17. Copenhagen, DK: SFI

Ejrnæs, M., Ejrnæs, M., \& Frederiksen, S. (2011). Risk factors of entry in out-of-home care: an empirical study of Danish birth cohorts, 1981-2003. Child Indicators Research, 4, 2144.

Esping-Andersen, G. (1990). The three worlds of welfare capitalism. Cambridge, UK: Polity Press.

Fallesen, P. (2013a). Downward Spiral: The impact of foster care placement on paternal public dependency. Presented at Annual Meeting of Population Association of America, 78th, 
New Orleans, LO.

Fallesen, P. (2013b). Time well spent: The duration of foster care and early adult labor market, educational, and health outcomes. Journal of Adolescence, 36, 1003-1011.

Fallesen, P., Emanuel, N. \& Wildeman, C. (2013). Den kumulative risiko for anbringelse uden for hjemmet. In S. H. Andersen \& P. Fallesen (Eds.): Når man anbringer et barn II: Årsager, effekter af anbringelsesforanstaltninger og konsekvenser (pp. 31-42). Odense, DK: University Press of Southern Denmark.

Frederiksen, S. (2012). Empirical essays on placements in outside home care. PhD-thesis, Aarhus University, School of Business and Social Sciences.

Gendell, S. J. (2001). In search of permanency. Family Court Review, 39, 25-42.

Gilbert, N. (2012). A comparative study of child welfare systems: Abstract orientations and concrete results. Children and Youth Services Review, 34, 532-536.

Hartley, E. K. (1984). Government leadership to protect children from foster care "drift". Child Abuse \& Neglect, 8, 337-342.

Havlicek, J. (2010). Patterns of movement in foster care: An optimal matching analysis. The Social Service Review, 84, 403-435.

Havlicek, J. (2011). Lives in motion: A review of former foster youth in the context of their experiences in the child welfare system. Children and Youth Services Review, 33, 10901100.

Hestbæk, A-D. (2011). Denmark: A child welfare system under reframing. In N. Gilbert, N. Parton \& M. Skivenes (Eds.): Child protection systems: International trends and orientations (pp. 131-153). New York, NY: Oxford University Press.

Lancee, B., \& Van de Werfhorst, H. G. (2012). Income inequality and participation: A 
comparison of 24 European countries. Social Science Research, 41, 1166-1178.

Lesnard, L. (2010). Setting cost in optimal matching to uncover contemporaneous sociotemporal patterns. Sociological Methods \& Research, 38, 389-419.

Lewis, E. E., Dozier, M., Ackerman, J., \& Sepulveda-Kozakowski, S. (2007). The effect of placement instability on adopted children's inhibitory control abilities and oppositional behavior. Developmental Psychology, 43, 1415-1426.

Nagin, D. S. (1999). Analyzing developmental trajectories: A semiparametric, group-based approach. Psychological Methods, 1, 139-157.

Newton, R. R., Litrownik, A. J., \& Landsverk, J. A. (2000). Children and youth in foster care: Disentangling the relationship between problem behaviors and number of placements. Child Abuse \& Neglect, 24, 1363-1374.

Oosterman, M., Schuengel, C., Slot, W. N., Bullens, R. A., \& Doreleijers, T. A. (2007). Disruptions in foster care: A review and meta-analysis. Children and Youth Services Review, 29, 53-76.

Perry, B. L. (2006). Understanding social network disruption: The case of youth in foster care. Social Problems, 53, 371-391.

Proch, K., \& Taber, M. A. (1985). Placement disruption: A review of research. Children and Youth Services Review, 7, 309-320.

Putnam-Hornstein, E., \& Needell, B. (2011). Predictors of child protective service contact between birth and age five: An examination of California's 2002 birth cohort. Children and Youth Services Review, 33, 1337-1344.

Putnam-Horstein, E., Needell, B., \& Rhodes, A. E. (2013). Understanding risk and protective factors for child maltreatment. The value of integrated, population-based data. Child 
Abuse \& Neglect, 37, 116-119.

Rubin, D. M., Alessandrini, E. A., Feudtner, C., Mandell, D. S., Localio, A. R., \& Hadley, T. (2004). Placement stability and mental health costs for children in foster care. Pediatrics, 113, 1336-1341.

Rubin, D. M., O'Reilly, A. L. R., Luan, X., \& Localio, A. R. (2007). The impact of placement stability on behavioral well-being for children in foster care. Pediatrics, 119, 336-344.

Simkiss, D. E., Stallard, N. \& Thorogood, M. (2013). A systematic literature review of the risk factors associated with children entering public care. Child: Care, Health and Development, 39, 628-642.

Statistics Denmark (2013). Kvalitetsdeklaration: Støtte til udsatte børn og unge. http://www.dst.dk/da/Statistik/dokumentation/kvalitetsdeklarationer/stoette-til-udsatte-boern-ogunge.aspx. Accessed 04/30/2014.

Ubbesen, M. B., Petersen, L., Mortensen, P. B., \& Kristensen, O. S. (2012). Out of care and into care again: A Danish register-based study of children placed in out-of-home care before their third birthday. Children and Youth Services Review, 34, 2147-2155.

United States Government Accountability Office (2013). Human Services - Sustained and Coordinated Efforts Could Facilitate Data Sharing While Protecting Privacy. Washington, DC: United States Government Accountability Office.

Usher, C. L., Randolph, K. A., \& Gogan, H. C. (1999). Placement patterns in foster care. Social Service Review, 73, 22-29.

Vaithianathan, R., Maloney, T., Putnam-Hornstein, E., \& Jiang, N. (2013). Children in the public benefit system at risk of maltreatment: identification via predictive modeling. American Journal of Preventive Medicine, 45, 354-359. 
Warburton, W. P., Warburton, R. N., Sweetman, A., \& Hertzman, C. (2014). The impact of placing adolescent males into foster care on education, income assistance, and convictions. Canadian Journal of Economics/Revue canadienne d'économique, 47, 35-69.

Ward, H. (2009). Patterns of instability: Moves within the care system, their reasons, contexts and consequences. Children and Youth Services Review, 31, 1113-1118.

Wells, K., \& Guo, S. (1999). Reunification and reentry of foster children. Children and Youth Services Review, 21, 273-294.

Wildeman, C. \& Emanuel, N. (2014). Cumulative Risks of Foster Care Placement by Age 18 for US Children, 2000-2011. PloS one, 9, e92785.

Wildeman, C., and Waldfogel, J. (forthcoming). Somebody's children or nobody's children? Sociological perspectives on the foster care system. Annual Review of Sociology.

Wu, L. L. (2000). Some comments on "Sequence analysis and optimal matching methods in sociology: Review and prospect". Sociological Methods \& Research, 29, 41-64. 
Table 1

Descriptive Statistics across Foster Care Careers

\begin{tabular}{|c|c|c|c|c|c|c|}
\hline Career Type & $\begin{array}{l}\text { Duration of } \\
\text { Foster Care } \\
\text { Placement(s) } \\
\text { in months }\end{array}$ & $\begin{array}{l}\text { Number of } \\
\text { Placements }\end{array}$ & $\begin{array}{l}\text { Age at } \\
\text { Start of } \\
\text { First } \\
\text { Placement }\end{array}$ & $\begin{array}{l}\text { Age at End } \\
\text { of Last } \\
\text { Placement }\end{array}$ & $\begin{array}{l}\text { Number of } \\
\text { Reentries } \\
\text { into Foster } \\
\text { Care }\end{array}$ & $\begin{array}{l}\text { Number } \\
\text { of } \\
\text { Children }\end{array}$ \\
\hline Short term 1 & $\begin{array}{c}24.45 \\
(14.82)\end{array}$ & $\begin{array}{c}1.70 \\
(1.03)\end{array}$ & $\begin{array}{l}14.28 \\
(2.84)\end{array}$ & $\begin{array}{l}17.13 \\
(0.96)\end{array}$ & $\begin{array}{c}0.37 \\
(0.69)\end{array}$ & 12217 \\
\hline Short term 2 & $\begin{array}{c}15.28 \\
(18.37)\end{array}$ & $\begin{array}{c}1.48 \\
(1.12)\end{array}$ & $\begin{array}{l}12.49 \\
(5.72)\end{array}$ & $\begin{array}{l}14.49 \\
(4.95)\end{array}$ & $\begin{array}{c}0.33 \\
(0.87)\end{array}$ & 11159 \\
\hline Stable 1 & $\begin{array}{l}169.54 \\
(34.09)\end{array}$ & $\begin{array}{c}1.80 \\
(1.08)\end{array}$ & $\begin{array}{c}2.53 \\
(1.47)\end{array}$ & $\begin{array}{l}17.27 \\
(2.12)\end{array}$ & $\begin{array}{c}0.32 \\
(0.59)\end{array}$ & 299 \\
\hline Stable 2 & $\begin{array}{c}95.54 \\
(25.35)\end{array}$ & $\begin{array}{c}1.85 \\
(1.01)\end{array}$ & $\begin{array}{c}9.07 \\
(1.43)\end{array}$ & $\begin{array}{l}17.27 \\
(1.24)\end{array}$ & $\begin{array}{c}0.28 \\
(0.56)\end{array}$ & 813 \\
\hline Stable 3 & $\begin{array}{c}49.35 \\
(15.00)\end{array}$ & $\begin{array}{c}1.54 \\
(0.76)\end{array}$ & $\begin{array}{l}13.18 \\
(1.12)\end{array}$ & $\begin{array}{l}17.37 \\
(0.94)\end{array}$ & $\begin{array}{c}0.18 \\
(0.43)\end{array}$ & 3021 \\
\hline Two stop 1 & $\begin{array}{l}183.20 \\
(26.08)\end{array}$ & $\begin{array}{c}3.16 \\
(1.44)\end{array}$ & $\begin{array}{c}1.35 \\
(1.12)\end{array}$ & $\begin{array}{l}17.57 \\
(1.44)\end{array}$ & $\begin{array}{c}0.81 \\
(0.85)\end{array}$ & 238 \\
\hline Two stop 2 & $\begin{array}{c}95.33 \\
(28.57)\end{array}$ & $\begin{array}{c}2.72 \\
(0.99)\end{array}$ & $\begin{array}{c}8.37 \\
(2.94)\end{array}$ & $\begin{array}{l}17.58 \\
(0.90)\end{array}$ & $\begin{array}{c}0.63 \\
(0.68)\end{array}$ & 900 \\
\hline Complex 1 & $\begin{array}{l}115.14 \\
(45.15)\end{array}$ & $\begin{array}{c}3.50 \\
(0.78)\end{array}$ & $\begin{array}{c}5.90 \\
(3.62)\end{array}$ & $\begin{array}{l}17.62 \\
(0.81)\end{array}$ & $\begin{array}{c}1.09 \\
(0.86)\end{array}$ & 673 \\
\hline Complex 2 & $\begin{array}{l}130.42 \\
(39.29) \\
\end{array}$ & $\begin{array}{c}6.13 \\
(1.82) \\
\end{array}$ & $\begin{array}{c}3.61 \\
(2.78) \\
\end{array}$ & $\begin{array}{l}17.53 \\
(1.16) \\
\end{array}$ & $\begin{array}{c}2.47 \\
(1.76) \\
\end{array}$ & 919 \\
\hline Total & $\begin{array}{c}35.49 \\
(39.66) \\
\end{array}$ & $\begin{array}{c}1.82 \\
(1.37) \\
\end{array}$ & $\begin{array}{c}12.47 \\
(21.31) \\
\end{array}$ & $\begin{array}{l}16.23 \\
(3.39) \\
\end{array}$ & $\begin{array}{c}0.43 \\
(0.89) \\
\end{array}$ & 30239 \\
\hline
\end{tabular}

Note: Standard deviations in parentheses.

Source: Own calculations on data from Statistics Denmark. 
Table 2

Foster Care Settings Experienced by Children across Careers for all Danish Foster Care Children Born 1982-1987 (Share of Children who Spent at least One Month in at Given Placement Type)

\begin{tabular}{|c|c|c|c|c|c|c|}
\hline Career Type & $\begin{array}{l}\text { Family } \\
\text { foster } \\
\text { care }\end{array}$ & $\begin{array}{l}\text { Congregate } \\
\text { and } \\
\text { institution } \\
\text { care }\end{array}$ & $\begin{array}{l}\text { Psychiatric } \\
\text { or somatic } \\
\text { hospital }\end{array}$ & $\begin{array}{l}\text { Treatment } \\
\text { care }\end{array}$ & $\begin{array}{l}\text { Boarding } \\
\text { and } \\
\text { continuation } \\
\text { school }\end{array}$ & Other \\
\hline Short term 1 & .241 & .223 & .001 & .161 & .674 & .144 \\
\hline Short term 2 & .319 & .281 & .002 & .086 & .416 & .133 \\
\hline Stable 1 & .842 & .264 & .003 & .130 & .130 & .070 \\
\hline Stable 2 & .737 & .347 & .001 & .159 & .262 & .096 \\
\hline Stable 3 & .424 & .277 & .000 & .216 & .420 & .128 \\
\hline Two stop 1 & .903 & .689 & .000 & .151 & .151 & .122 \\
\hline Two stop 2 & .794 & .506 & .000 & .258 & .273 & .122 \\
\hline Complex 1 & .835 & .649 & .004 & .273 & .217 & .098 \\
\hline Complex 2 & .932 & .769 & .009 & .323 & .237 & .177 \\
\hline Average & .363 & .292 & .002 & .148 & .497 & .135 \\
\hline
\end{tabular}


Table 3

Summary of Logistic Regression Analysis for Variables Predicting Entrance into Complex

Careers for All Children ( $\mathrm{n}=30239)$ and All Long Term Career Children $(\mathrm{n}=6863)$

\begin{tabular}{|c|c|c|c|c|c|c|}
\hline \multirow[b]{2}{*}{ Predictor } & \multicolumn{3}{|c|}{ All careers } & \multicolumn{3}{|c|}{ Long term careers } \\
\hline & B & S.E. & OR & B & S.E. & OR \\
\hline Child's gender, female $=1$ & $-0.14^{*}$ & 0.06 & 0.83 & 0.02 & 0.07 & 1.03 \\
\hline \multicolumn{7}{|l|}{ Mother's family status } \\
\hline Living w. father & $-0.30^{* *}$ & 0.10 & 0.74 & -0.14 & 0.11 & 0.87 \\
\hline Cohabiting & $-0.37^{* * *}$ & 0.09 & 0.69 & $-0.34^{* * *}$ & 0.10 & 0.71 \\
\hline Divorced & $-0.36^{* *}$ & 0.11 & 0.70 & $-0.35^{* *}$ & 0.13 & 0.70 \\
\hline Father dead & $-0.51^{*}$ & 0.26 & 0.60 & -0.47 & 0.29 & 0.62 \\
\hline Mother dead & $3.20^{* * *}$ & 0.30 & 24.54 & $1.92^{* * *}$ & 0.31 & 6.82 \\
\hline Child is orphaned & $3.64^{* * *}$ & 0.27 & 38.06 & $2.58^{* * *}$ & 0.33 & 13.14 \\
\hline Father missing & $0.70^{* * * *}$ & 0.13 & 2.03 & $0.59^{* * *}$ & 0.16 & 1.80 \\
\hline Mother missing & $1.60^{* * *}$ & 0.39 & 4.95 & 0.68 & 0.41 & 1.98 \\
\hline \multicolumn{7}{|l|}{ Family stability } \\
\hline Changed partner & 0.07 & 0.09 & 1.07 & 0.13 & 0.09 & 1.14 \\
\hline Moved residence & $0.96^{* * *}$ & 0.09 & 2.61 & $0.70^{* * *}$ & 0.10 & 2.02 \\
\hline \multicolumn{7}{|l|}{ Mother's employment } \\
\hline Unemployed & $0.26^{* *}$ & 0.10 & 1.30 & 0.12 & 0.10 & 1.13 \\
\hline Early retirement & $0.34^{* *}$ & 0.11 & 1.41 & 0.12 & 0.12 & 1.12 \\
\hline Sick leave & $-1.98^{* *}$ & 0.72 & 0.14 & $-1.63^{*}$ & 0.37 & 0.20 \\
\hline Outside labor force & $1.48^{* * *}$ & 0.08 & 4.39 & $1.13^{* * *}$ & 0.08 & 3.09 \\
\hline \multicolumn{7}{|l|}{ Socioeconomic background } \\
\hline Education & $-0.70^{* * *}$ & 0.08 & 0.50 & $-0.51^{* * *}$ & 0.09 & 0.60 \\
\hline Mother's age at birth & $0.03^{* * *}$ & 0.01 & 1.03 & $0.02^{* *}$ & 0.01 & 1.02 \\
\hline Danish native, yes $=1$ & $1.37^{* * *}$ & 0.17 & 3.92 & $0.65^{* *}$ & 0.23 & 1.91 \\
\hline Western immigrant, yes $=1$ & $1.13^{* *}$ & 0.26 & 3.10 & $0.60^{*}$ & 0.29 & 1.82 \\
\hline$N$ & \multicolumn{3}{|c|}{30239} & \multicolumn{3}{|c|}{6863} \\
\hline$\chi^{2}$ & \multicolumn{3}{|c|}{1648.59} & \multicolumn{3}{|c|}{753.49} \\
\hline$D f$ & \multicolumn{3}{|c|}{19} & \multicolumn{3}{|c|}{19} \\
\hline$\%$ in complex careers & \multicolumn{3}{|c|}{5.26} & \multicolumn{3}{|c|}{23.20} \\
\hline
\end{tabular}

Note: All variables measured the year prior to first placement. Constant term not shown. OR $=$ Odds ratio. Father/Mother missing: Individual not present in Denmark, but not recorded as deceased. Changed partner: Mother changed partner in the last year, yes $=1$, no $=0$. Moved: Mother moved residence in the last year. Education: Mother had education at least at high school level, yes $=1$, no $=0$. Single mother is reference for family status. In work is reference for employment. Immigration status on basis of mother's place of birth-Non-western is reference for nativity. ${ }^{*} p<0.05,{ }^{* *} p<0.01,{ }^{* * *} p<0.001$.

Source: Own calculation on data from Statistics Denmark. 
Figure 1

Example of monthly foster care sequences

(a) Example of Foster Care Event Patterns for 12 Months for Two Children

\begin{tabular}{|l|l|l|l|c|c|c|c|c|c|c|c|}
\multicolumn{1}{c|}{} & 1 & 2 & 3 & 4 & 5 & 6 & 7 & 8 & 9 & 10 & 11 \\
\cline { 2 - 12 } \multicolumn{1}{c|}{ Child 1 } & Home & Pl. 1 & Pl. 1 & Pl. 1 & Pl. 1 & Pl. 1 & Pl. 2 & Pl. 2 & Pl. 2 & Pl. 2 & Pl. 2 \\
\hline Child 2 & Home & Home & Home & Home & Pl. 1 & Pl. 1 & Home & Pl. 2 & Pl. 2 & Pl. 3 & Pl. 3 \\
\hline
\end{tabular}

(b) Months with Identical Sequences

\begin{tabular}{|l|l|l|l|c|c|c|c|c|c|c|c|}
\multicolumn{1}{c|}{} & \multicolumn{1}{c|}{1} & 2 & 3 & 4 & 5 & 6 & 7 & 8 & 9 & 10 & 11 \\
\hline Child 1 & Home & Pl. 1 & Pl. 1 & Pl. 1 & Pl. 1 & Pl. 1 & Pl. 2 & Pl. 2 & Pl. 2 & Pl. 2 & Pl. 2 \\
\hline Child 2 & Home & Home & Home & Home & Pl. 1 & Pl. 1 & Home & Pl. 2 & Pl. 2 & Pl. 3 & Pl. 3 \\
\hline
\end{tabular}

(c) Months with Different Sequences

Month of Childhood

\begin{tabular}{|l|l|l|l|l|c|c|c|c|c|c|c|}
\cline { 2 - 10 } \multicolumn{1}{c|}{} & 1 & \multicolumn{1}{c|}{2} & 3 & 4 & 5 & 6 & 7 & 8 & 9 & 10 & 11 \\
\hline Child 1 & Home & Pl. 1 & Pl. 1 & Pl. 1 & Pl. 1 & Pl. 1 & Pl. 2 & Pl. 2 & Pl. 2 & Pl. 2 & Pl. 2 \\
\hline Child 2 & Home & Home & Home & Home & Pl. 1 & Pl. 1 & Home & Pl. 2 & Pl. 2 & Pl. 3 & Pl. 3 \\
\hline
\end{tabular}


Figure 2

Distribution of Overall Duration of Foster Care Stays for 1982-1987 Cohorts

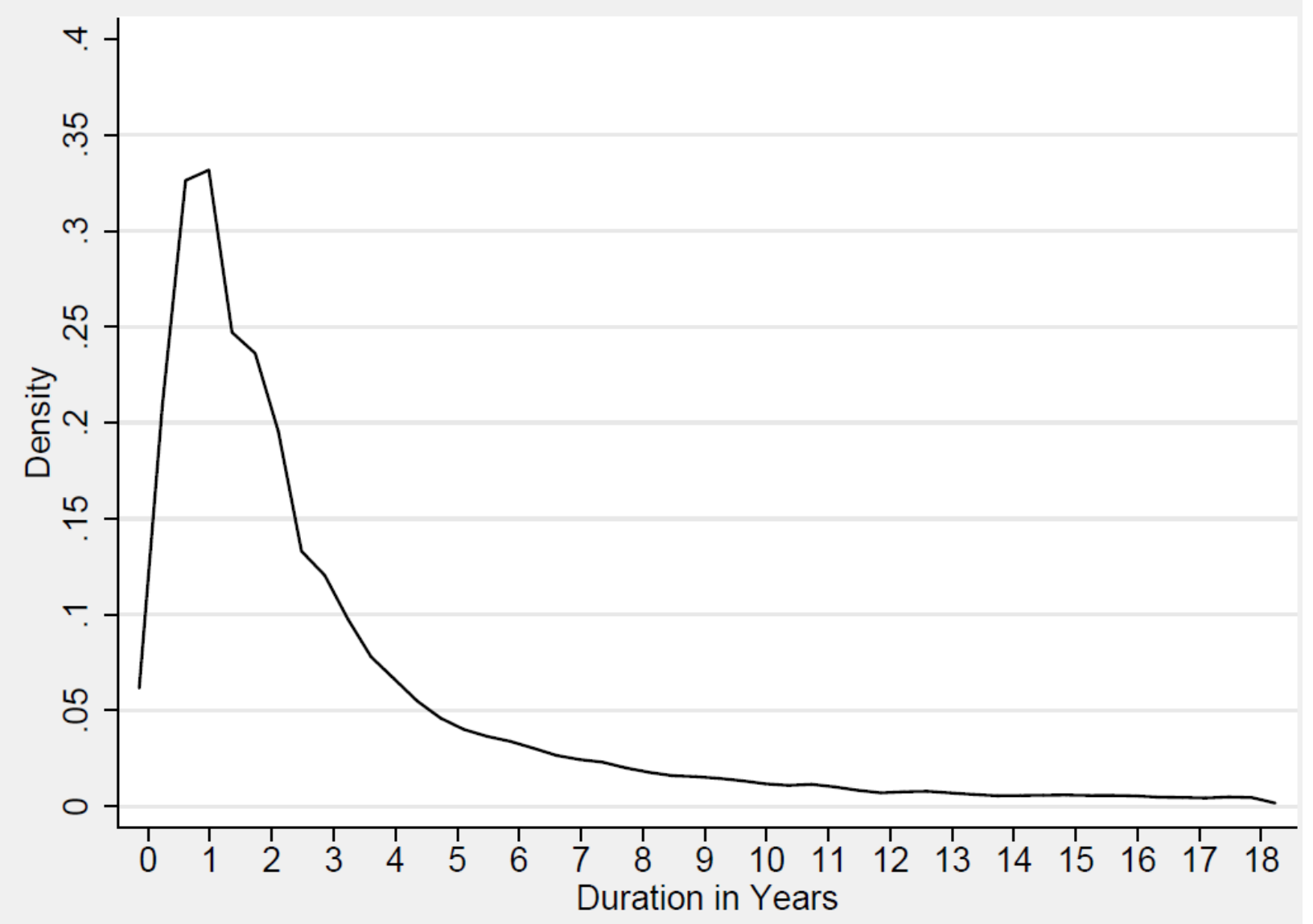

Source: Own calculation on data from Statistics Denmark. 


\section{Figure 3}

State Distribution Plots for Foster Care Careers for all Danish Foster Care Children Born 1982-1987
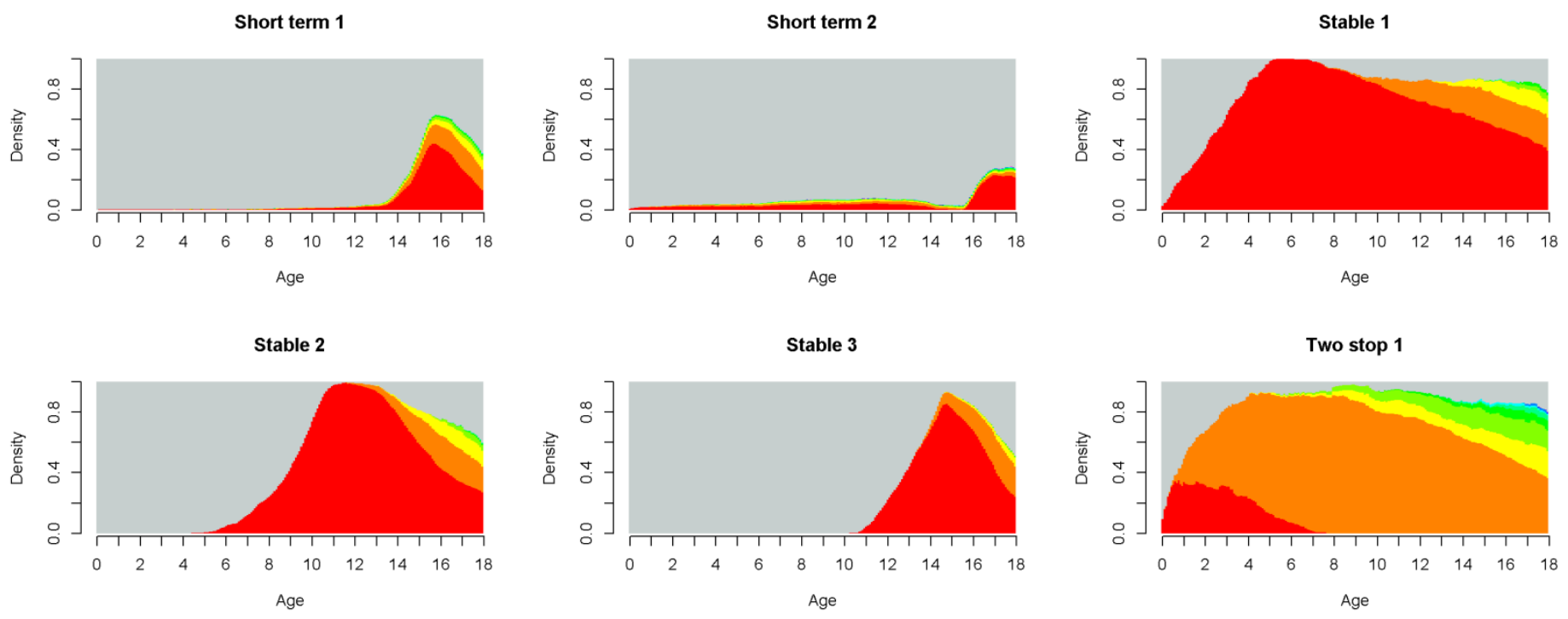

Two stop 2

Complex 1
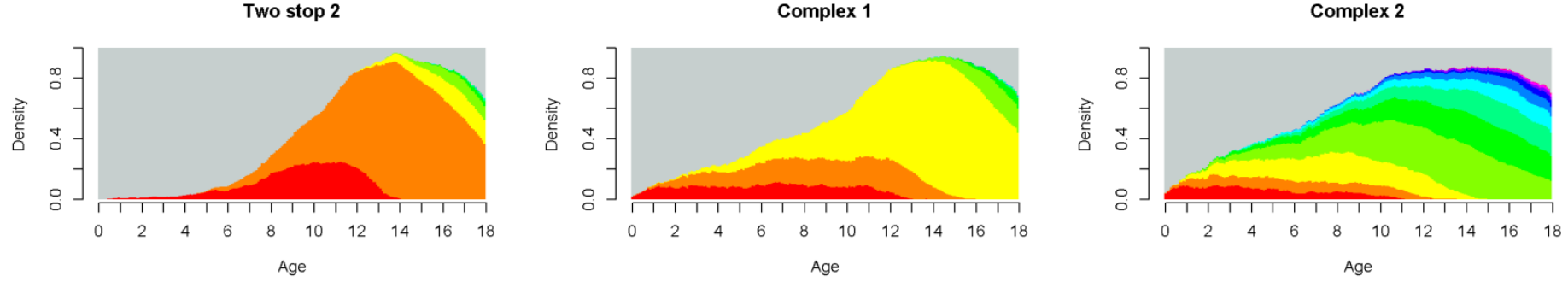

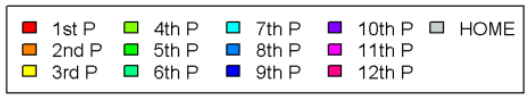

Source: Own calculations on data from Statistics Denmark. 
Figure 4

Sequence Index Plots for Career Types for all Danish Foster Care Children Born 1982-1987 (Each line in the plot represents one child's foster care trajectory from birth to adulthood)

Short term 1

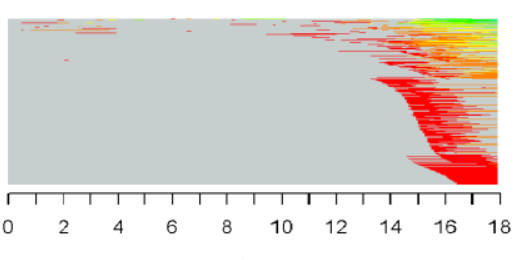

Age

Stable 2

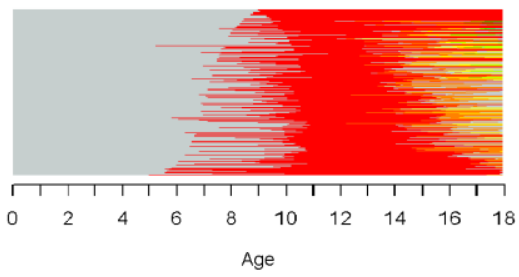

Two stop 2

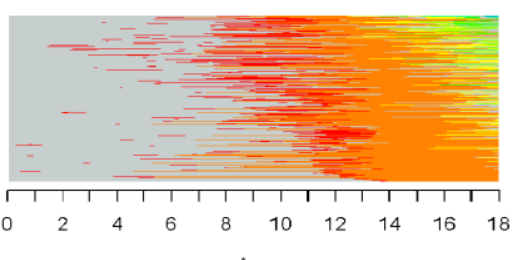

Age
Short term 2

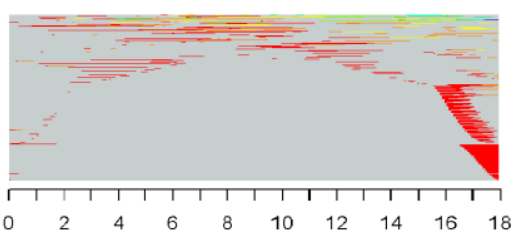

Age

Stable 3

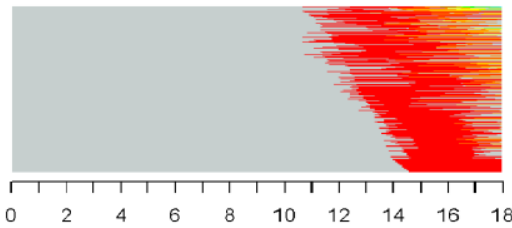

Age

Complex 1

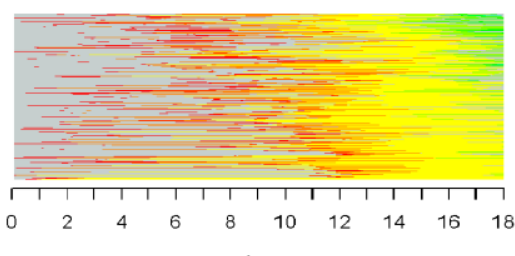

Age

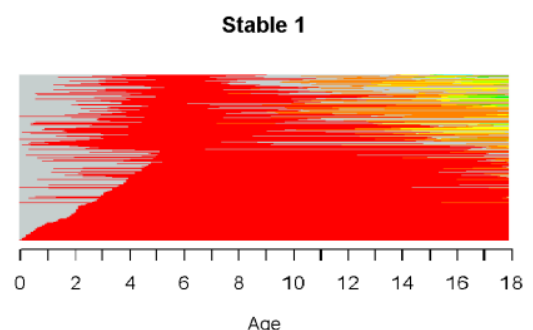

Age

Two stop 1

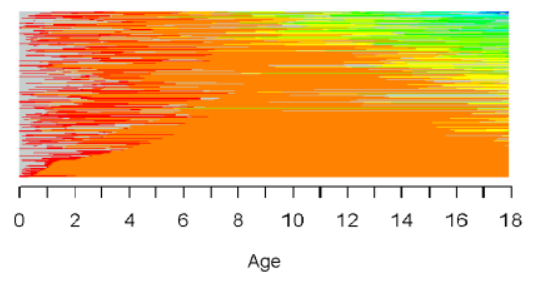

Complex 2

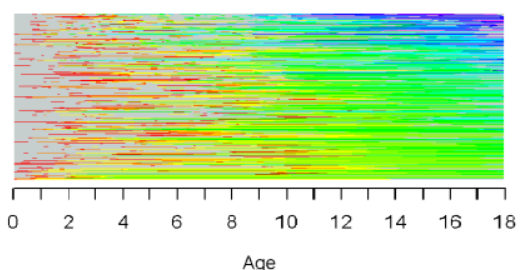

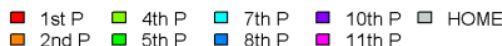

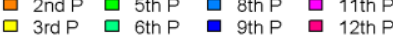

Source: Own calculations on data from Statistics Denmark. 


\section{Appendix}

Table A1

Descriptive statistics for sample

Variable

Child's gender, female $=1$

Mean

.45

Mother's family status

Single

Living w. father

Cohabiting

Divorced

Father dead

Mother dead

Child is orphaned

Father missing

Mother missing

Family stability

Changed partner

Moved residence

Mother's employment

In work/studying

Unemployed

Early retirement

Sick leave

Outside labor force

Mother's socioeconomic background

Education

Mother's age at birth

Danish native

Western immigrant

Non-western immigrant $N$

$.13 \quad .37$

$.25 \quad .43$

$.32 \quad .47$

$\begin{array}{ll}.18 & .39\end{array}$

$.02 \quad .14$

$.03 \quad .18$

$.03 \quad .18$

$.03 \quad .17$

$.03 \quad .16$

$.14 \quad .35$

.12 .33

$.57 \quad .49$

$.19 \quad .39$

$\begin{array}{ll}.09 & .29\end{array}$

$.02 \quad .14$

$.13 \quad .33$

$.34 \quad .47$

$22.30 \quad 8.70$

$\begin{array}{ll}.81 & .39\end{array}$

$.03 \quad .16$

$.16 \quad .37$

30239

Note: All variables measured the year prior to first placement. Father/Mother missing:

Individual not present in Denmark, but not recorded as deceased. Changed partner: Mother changed partner in the last year, yes $=1$, no $=1$. Moved residence: Mother moved residence in the last year. Education: Mother had education at least at high school level, yes =1, no =1. Single mother is reference for family status, and is defined as being the sole adult of that generation in the household and unmarried. In work is reference for employment. Immigration status on basis of mother's place of birth-Non-western is reference. Western countries is coded using Statistics Denmark's definition, which include the Nordic countries, pre-2008 EU member countries, Andorra, Lichtenstein, Monaco, San Marino, Switzerland, the Vatican State, Canada, U.S., Australia, and New Zealand.

Source: Own calculation on data from Statistics Denmark. 


\section{Supplement Material: Cost-setting in Dynamic Hamming Matching}

The following material shows how DHM calculates the transition costs for any transition between two states in the data:

$$
S_{t}(m, n)=\left\{\begin{array}{c}
4-g_{t}(m, n) \text { if } n \neq m \\
\text { 0otherwise }
\end{array}\right.
$$

where

$$
\begin{gathered}
g_{t}(m, n)=P\left(X_{t}=m \mid X_{t-1}=n\right)+P\left(X_{t+1}=m \mid X_{t}=n\right)+ \\
P\left(X_{t}=n \mid X_{t-1}=m\right)+P\left(X_{t+1}=n \mid X_{t}=m\right)
\end{gathered}
$$

$S_{t}(m, n)$ is the cost for aligning sequence $n$ and $m$ at period $t$. The cost is set at 4 minus the share of children in the data who move between $n$ and $m$ around period $t$ (expressed as $\left.g_{t}(m, n)\right)$. The fewer moves in the data around period $t$, the closer the cost is to 4 . The more moves, the closer the cost is to 0 . Summarizing transition costs across sequences for all pairs of children in the data yields a $N \times N$ matrix of dissimilarity measures that describe how dissimilar any two childhood-trajectories in the data are from each other:

$$
D\left(i_{1}, i_{2}\right)=\sum_{t=1}^{T} s_{t}\left(i_{1}, i_{2}\right)
$$

We can then perform hierarchical cluster analysis on the dissimilarity matrix, thereby creating groups of children who have similar foster care trajectories. The stopping rules 
proposed by Duda, Hart, \& Stork (2012) and Caliński and Harabasz (1974) aid in locating the best fitting number of clusters.

\section{References}

Caliński, T., \& Harabasz, J. (1974). A dendrite method for cluster analysis.

Communications in Statistics-theory and Methods, 3(1), 1-27.

Duda, R. O., Hart, P. E., \& Stork, D. G. (2012). Pattern classification. New York, NY: Wiley. 